This document is the Accepted Manuscript version of a Published Work that appeared in final form in International Journal of Therapy and Rehabilitation, copyright (C) MA Healthcare, after peer review and technical editing by the publisher. To access the final edited and published work see https://doi.org/10.12968/ijtr.2017.0117. 
Original research

\section{The time-course effects of talus taping on ankle dorsiflexion range of motion}

David J Dearlove, Faculty of Health, Social Care and Education, Kingston University and St George's, University of London, London, UK; Ellesse Newman, Faculty of Health, Social Care and Education, Kingston University and St George's, University of London, London, UK; Matt Zasada, Faculty of Health, Social Care and Education, Kingston University and St George's, University of London, London, UK

Correspondence to: David J Dearlove (david.dearlove@dpag.ox.ac.uk)

\section{Abstract}

Background: Talus taping may be an effective physiotherapeutic treatment for equinus (passive dorsiflexion range of motion $<10^{\circ}$ ). However, the time-course effects of this intervention are unknown.

Methods: Sixteen healthy participants (mean age $28.3 \pm 8$ years) were recruited. Participants' ankles were randomly assigned to control and intervention conditions. Baseline measures of dorsiflexion range of motion were taken in both ankles using the weight-bearing lunge test. The intervention ankle had talus tape applied, which remained in place for 48 hours during normal functional activities. To determine the time-course effects, dorsiflexion range of motion was reassessed in the control and intervention ankles immediately following removal of the tape (at 48 hours) and again 5 days later, on day 7.

Findings: Dorsiflexion range of motion in the taped intervention ankle increased significantly between the baseline and 48-hour measures. However, when reassessed at day 7, participants' 
dorsiflexion ranges of motion had returned to baseline levels. There were no significant differences in the control ankle across all three measures.

Conclusions: Applying talus tape for 48 hours during normal functional activities results in immediate but not long-lasting changes in dorsiflexion range of motion.

\section{KEY WORDS}

Dorsiflexion range of motion, Equinus, Talus taping

\section{Introduction}

Equinus is a condition commonly defined as $<10^{\circ}$ passive dorsiflexion (DF) range of motion (ROM) (Root et al, 1977) at the ankle. Its aetiologies include: genetic inheritance (Sobel et al, 1997); ageing (Grimston et al, 1993); diabetes mellitus (Zimny et al, 2004); immobility following lowerextremity injury (Kerkhoffs et al, 2001); and neurological impairment (Peng et al, 2011). While equinus may not observably impact an individual's functional capacity (Moseley et al, 2001), its presence may result in compensatory pathomechanics (Burnfield and Perry, 2010; Macrum et al, 2012), which can increase an individual's susceptibility to lower-extremity injuries, including: ankle sprain (Terada et al, 2013); plantar fasciitis (Riddle et al, 2003); Achilles tendinitis; stress fractures; shin splints (Wilder and Sethi, 2004); iliotibial band syndrome (Neely, 1998); patellofemoral syndrome (Dill et al, 2014); patellar tendinopathy (Malliaras et al, 2006); and anterior cruciate ligament tear (Fong et al, 2011). As such, addressing modifiable deficiencies in DF ROM is a priority for physiotherapists seeking to attenuate lower-extremity injury risk factors (Terada et al, 2013).

DF occurs predominately at the talocrural (tibiotalar) joint, and to a lesser extent at the subtalar joint (Valderrabano et al, 2006). During DF, the convex talus glides posteriorly on the concave ankle mortise formed by the tibia and fibula heads (Sammarco et al, 1973). Limitations in 
the posterior glide of the talus, secondary to insufficient soft tissue extensibility and/or osseous restrictions (Tiberio, 1988), may result in equinus. Sahrmann (2011) described a 'talus taping' intervention to address restricted posterior glide of the talus. The intervention applies an anteriorposterior stabilising force to the talus during tibial advancement over a fixed foot. Sahrmann hypothesised that this would enhance the posterior glide of the talus, resulting in increased tibial advancement and, therefore, DF ROM.

Four published studies have reported significant increases in DF ROM following a talus taping intervention (Kang et al, 2013; 2014; Yoon et al, 2014a; 2014b); however, none have investigated the time-course effects of the intervention. As such, it is currently unknown whether the observed increases in ROM are transient or longer lasting. Further, participants performed controlled activities in a laboratory with the tape applied for 5-10 minutes. While to the authors' knowledge there are no published guidelines stating the optimum duration for which physiotherapeutic tape should be applied, tape is commonly applied for 24-48 hours during normal functional activities. As such, the generalisability of existing research findings is limited.

Given this, the objectives of this study were twofold. First, we sought to identify the effect that the application of talus tape for 48 hours during normal functional activities has on DF ROM. Second, we aimed to determine whether any changes in DF ROM persisted until 5 days post removal (study day 7). These findings will help inform clinical reasoning for physiotherapists managing patients presenting with equinus.

\section{Subjects and methods}

A single-blinded, within-subject pilot study was conducted to investigate the time-course effects of talus taping on DF ROM. A convenience sample of 20 volunteers (11 males and nine females) was recruited from St George's, University of London (SGUL) by public noticeboard 
advertisements and following announcements at preregistration physiotherapy lectures. The exclusion criteria were lower-extremity injury within the previous 6 months, previous fracture or dislocation of the ankle, history of chronic instability of the ankle, hypermobility, a known neurological disorder and any condition that would contraindicate taping. All subjects gave informed consent before participating. The Faculty of Health, Social Care and Education, Kingston University and SGUL granted ethical approval for this study. This study was conducted in accordance with the principles of the Helsinki Declaration. Subjects' anonymity and confidentiality were assured.

Subjects reported to the SGUL physiotherapy laboratory on three occasions over 7 days. At visit 1 , a true random number generator was used to determine the control and intervention ankle for each participant. Assessors were blinded to this allocation. Baseline measures of DF ROM were taken on both ankles using a weight-bearing lunge test (WBLT), which has previously been reported to produce high intra-rater reliability (Powden et al, 2015). The left ankle was measured first in all subjects. To ensure any taping residues/marks were concealed from assessors, Stockinets (FLA Orthopaedics, Inc, Florida, USA) were used to cover both ankles. The WBLT was performed as previously described by Bennell et al (1998). The same two investigators assessed the WBLT across all trials. All subsequent measures of DF ROM were performed in an identical fashion. Following completion of baseline testing, the participant's intervention ankle was taped. Each participant lay supine on a plinth with his or her ankles and feet unsupported and asked to perform maximum passive plantar flexion. Fixing tape was applied without pressure from the anterior talus passing inferiorly to the medial and lateral malleoli and attaching to the plantar surface of the calcaneus. A strip of zinc oxide tape was applied over the fixing tape with an anterior-to-posterior force on the talus. A single study investigator performed all taping. Advice was given not to submerge the tape in water and an information sheet regarding adverse events was supplied to each participant. The 
tape remained in place for 48 hours while the participant performed his or her normal activities of daily living. No intervention was performed on the control ankle. Approximately 48 hours after visit 1, the participant returned to the testing facilities for tape removal and a second measure of DF ROM in the intervention and control ankles. The final study visit and DF ROM measurements were completed 5 days later (test day 7). A 7-day timeframe was chosen to reflect a typical gap between treatment sessions.

To determine whether there was a statistically significant interaction between the two independent variables (taping and time), two-way repeated measures analysis of variance was used. All data were checked for normality before statistical comparison with the KolmogorovSmirnov and Shapiro-Wilk tests. Data were also tested for sphericity with Mauchly's test. To detect simple main effects in post hoc tests, related $t$-tests for relevant group comparisons were used with Bonferroni corrections. Statistical analysis was performed with IBM SPSS statistics desktop V22.0 for Mac OS (SPSS, Inc, Chicago, IL, USA). Statistical significance was considered at $P<0.05$.

\section{Findings}

Of the 20 volunteers, three were lost to follow-up and one was excluded due to significant deviation from the protocol. As such, 16 subjects (eight men and eight women) with a mean age of $28.3 \pm 8$ years completed the trial.

The mean DF ROM scores and SDs for each condition can be found in Table 1.

Table 1. Dorsiflexion range of motion for control and intervention ankles

\begin{tabular}{|l|l|l|l|}
\hline & Baseline $\mathbf{( c m )}$ & 48 hours $(\mathbf{c m})$ & $\mathbf{7}$ days $(\mathbf{c m})$ \\
\hline Intervention ankle $($ mean \pm SD) & $14.4 \pm 2.9$ & $15.5 \pm 3.1^{*}$ & $14.3 \pm 2.6$ \\
\hline Control ankle (mean \pm SD) & $13.8 \pm 2.3$ & $14.1 \pm 2.3$ & $13.8 \pm 2.4$ \\
\hline
\end{tabular}

* $P=0.003$ between baseline and 48 hours; $P=0.001$ between 48 hours and 7 days 
Kolmogorov-Smirnov and Shapiro-Wilk tests of normality indicated that all data were significantly normal. Mauchly's test of sphericity indicated that the assumption of sphericity was not violated in this sample. Consequently, all parametric assumptions to perform an analysis of variance were met.

There was a significant interaction effect between the intervention and time $(F(2,30)=4.31$; $P=0.023)$. To explore the interaction through simple main effects, post hoc repeated-measures $t$ tests were carried out with Bonferroni corrections $(\alpha=0.05 / 5=0.01)$. For the treatment ankle, there was a significant difference in DF ROM between baseline and 48-hour measures $(t(15)=-3.59$; $P=0.003)$ and between 48-hour and 7-day measures $(t(15)=4.16 ; P=0.001)$. However, there was no significant difference in DF ROM between baseline and 7-day measures $(t(15)=0.744 ; P=0.911)$. Within the control ankle, there was no significant difference between baseline and 48-hour measures $(t(15)=-1.66 ; P=0.117)$ or between 48-hour and 7-day measures $(t(15)=1.06 ; P=0.307)$.

\section{Discussion}

The present study found that DF ROM increased significantly from baseline to 48 hours in the taped treatment ankle but returned to baseline by day 7. In contrast, DF ROM did not significantly differ across all three measures in the control ankle. This finding suggests that talus taping achieves only transient increases in DF ROM.

Our finding that talus taping applied for 48 hours during normal functional activities achieves immediate increases in DF ROM is consistent with previous research (Kang et al, 2013; 2014; Yoon et al, 2014a; 2014b) where the tape was applied for 5-10 minutes during controlled activity. Despite these differences in intervention prescription, mean increases in DF ROM were comparable. Previously published studies used goniometry (angles in degrees) to measure changes, whereas we employed the WBLT (cm). Bennell and Colleagues $(\underline{1998})$ proposed that every $1 \mathrm{~cm}$ 
measured in the WBLT equates to approximately $3.6^{\circ}$ of ankle DF. As such, the mean $1.1 \mathrm{~cm}$ difference observed between baseline and 48-hour measures in the present study would equate to a $3.96^{\circ}$ increase. This is comparable to results reported in previously published studies, where immediate increases in DF ROM ranged from $4.11^{\circ}$ to $6.22^{\circ}$ (Kang et al, 2013; 2014; Yoon et al, 2014a; 2014b). Given this, we may infer that applying talus tape for 48 hours during normal functional activities does not yield greater immediate improvements in DF ROM than its application during 5-10 minutes of controlled activities. This finding suggests a ceiling effect that is reached within 5 minutes is and not enhanced by prolonging the intervention. To the authors' knowledge there are no published guidelines, systematic reviews or well-controlled clinical trials for physiotherapists to consult when determining the optimum duration for taping interventions. Our finding suggests these are warranted, particularly in light of the anecdotal observation that physiotherapists typically apply tape for 24-48 hours during normal functional activities.

To the authors' knowledge, this is the first study to investigate whether talus taping achieves persistent changes in DF ROM, as measured 5 days after removal of the tape. We found a non-significant difference between baseline and 7-day measures of DF ROM in the test ankle. This result raises questions about the utility of talus taping in achieving long-lasting changes in DF ROM. However, it remains unclear whether the use of talus taping as an adjunct to other treatment modalities would yield more persistent changes in DF ROM. Furthermore, in some cases transient changes in ROM may still be a valid clinical outcome, for example by providing a 'window of opportunity' allowing patients to restore normal movement and thus prevent compensatory pathomechanics that may perpetuate an injury.

Hypotheses for the mechanisms causing this study's observed transient increases in DF ROM may be categorised as biomechanical, neurophysiological and/or psychological. The biomechanical paradigm proposes that increases in DF ROM are achieved through changes in arthrokinematics 
secondary to the correction of a minor positional fault(s) (Vicenzino et al, 2007) and/or changing the excursion of non-contractile tissues surrounding the ankle (Threkland, 1992). Both could inhibit posterior glide of the talus and, therefore, reduce DF ROM. Given that our subjects had no history of ankle injury within the previous 6 months and did not present with limitations in DF ROM, it seems unlikely that the observed changes were secondary to the correction of a positional fault. A more plausible biomechanical explanation is that the repeated load applied to the viscoelastic tissues, providing passive stability to the talocurural joint, caused them to progressively deform until a new resting length was achieved (Threkland, 1992). However, with the load being within the elastic limits of the tissue, the tissue gradually returned to the original resting length once the load was removed, hence the DF ROM returning to baseline at day 7. It would be interesting to investigate the time-course effects of talus taping in individuals with known restrictions in DF ROM, who may benefit from the correction of minor positional faults.

The potential neurophysiological effects of talus taping are seldom considered. This paradigm hypothesises that talus tape might stimulate sensory receptors, which change the afferent input to the central nervous system (MacGregor et al, 2005). Prolonged altered afferent input from these receptors may lead to a change in motor neuron excitability, which could affect osetokinematics (Franettovich et al, 2008). Indeed, Yoon et al (2013) found increased and decreased activation of the gastrocnemius and tibialis anterior, respectively, during incline walking with talus tape. Yet it is difficult to establish cause and effect for the reported changes in muscle activity; tape-induced changes in muscle activation could be secondary to the biomechanical effects detailed above, rather than through changes in afferent input to the central nervous system. However, studies that applied tape with no theoretical biomechanical effects have reported changes in muscle activation (Alexander et al, 2008), thus advocating a neurophysiological component to our observed results. The proposed neurophysiological effects appear to be short- 
lived. Alexander et al (2008) found that applying a single strip of tape along the length of the triceps surae reduced the excitability of motor neurons, as measured by the $\mathrm{H}$ reflex; however, motor neuron inhibition ceased immediately upon removal of the tape. Kulkulka et al (1986) produced similar results, finding that pressure applied on the Achilles tendon reduced soleus $\mathrm{H}$ reflex amplitude, which returned to baseline within 5-10 seconds upon release of the pressure. Therefore, it appears that motor neuron excitation/inhibition lasts for as long as the stimulus (in this case, tape) is applied. In our study, there was an approximate 1-2-minute delay between removing the tape and taking the 48-hour measure. If the observed changes in DF ROM were neurophysiological in nature, given the elapsed time we might expect DF ROM to have already returned to baseline levels.

The psychological paradigm arises from a study limitation: the majority $(13 / 16,81.25 \%)$ of enrolled participants were undergraduate physiotherapy students. Participants were informed that the study was investigating whether talus taping affects movement of the ankle. However, given the sample population's predominant occupation, it is unlikely that sufficient blinding to the study's dependent variable (DF ROM) was achieved. Participants' expectations of the intervention might have contributed to the observed changes in DF ROM (Bialosky et al, 2010).

\section{Limitations and future research}

The limitations of the current study may guide future research. The present study design did not facilitate hypothetical testing of the potential mechanisms (biomechanical, neurophysiological and psychological) causing the reported increases in DF ROM. Further research is required to elucidate the exact mechanisms of this study's observed transient increases in DF ROM. Second, we recruited healthy volunteers with no known equinus (passive DF ROM $<10^{\circ}$ ). It is possible that the observed treatment effects would be different in participants presenting with equinus. However, 
comparable immediate increases in DF ROM were reported by prior studies (Kang et al, 2013; 2014; Yoon et al, 2014a; 2014b) that had recruited volunteers with DF ROM $<10^{\circ}$. Given that the immediate effects of the taping intervention appear to be comparable between symptomatic and asymptomatic volunteers, it seems plausible that any longer-term effects might also be comparable. As such, we propose our findings are likely generalisable to patients with equinus. Further, our recruitment of asymptomatic volunteers may explain why DF ROM reached statistical significance at 48 hours, but was below the reported $1.9 \mathrm{~cm}$ intra-clinician minimal detectable change (Malliaras et al, 2006).

\section{Conclusion}

In volunteers presenting with no restrictions in DF ROM, wearing talus tape for 48 hours during normal functional activities results in immediate, but not persisting, changes in DF ROM. This finding leads to questions about the clinical efficacy of talus taping. It is not known whether the use of talus tape as an adjunct to other physiotherapeutic interventions might yield more persistent treatment effects or whether persistent changes may be observed in participants with equinus.

\section{Acknowledgements}

The authors would like to thank Jasmin Meier, Sonny Sheppard and Tonje Gumdal Eidem for their valuable contributions to the manuscript.

\section{Conflict of Interest}

The authors declare no conflicts of interest. 


\section{References}

Alexander CM, McMullan M, Harrison PJ. What is the effect of taping along or across a muscle on motoneurone excitability? A study using triceps surae. Man Ther. 2008;13(1):57-62.

https://doi.org/10.1016/j.math.2006.08.003

Bennell KL, Talbot RC, Wajswelner H, et al. Intra-rater and inter-rater reliability of a weight-bearing lunge measure of ankle dorsiflexion. Aust J Physiother. 1998;44(3):175-180

Bialosky JE, Bishop MD, Cleland JA. Individual expectation: an overlooked, but pertinent, factor in the treatment of individuals experiencing musculoskeletal pain. Phys Ther. 2010;90(9):1345-1355. https://doi.org/10.2522/ptj.20090306

Burnfield J, Perry J. Gait analysis: normal and pathological function. New Jersey (NJ): Slack Incorporated; 2010

Dill KE, Begalle RL, Frank BS, Zinder SM, Padua DA. Altered knee and ankle kinematics during squatting in those with limited weight-bearing-lunge ankle-dorsiflexion range of motion. J Athl Train. 2014;49(6):723-732. https://doi.org/10.4085/1062-6050-49.3.29

Fong CM, Blackburn JT, Norcross MF, McGrath M, Padua DA. Ankle-dorsiflexion range of motion and landing biomechanics. J Athl Train. 2011;46(1):5-10. https://doi.org/10.4085/1062-6050-46.1.5

Franettovich M, Chapman A, Blanch P, Vicenzino B. A physiological and psychological basis for antipronation taping from a critical review of the literature. Sports Med. 2008;38(8):617-631. https://doi.org/10.2165/00007256-200838080-00001

Grimston SK, Nigg BM, Hanley DA, Engsberg JR. Differences in ankle joint complex range of motion as a function of age. Foot Ankle. 1993;14(4):215-222 
Kang MH, Kim JW, Choung SD, et al. Immediate effect of walking with talus-stabilizing taping on ankle kinematics in subjects with limited ankle dorsiflexion. Phys Ther Sport. 2014;15(3):156-161. https://doi.org/10.1016/j.ptsp.2013.09.001

Kang $\mathrm{MH}$, Kim JW, Kim MH, et al. Influence of walking with talus taping on the ankle dorsiflexion passive range of motion. J Phys Ther Sci. 2013;25(8):1011-1013.

https://doi.org/10.1589/jpts.25.1011

Kerkhoffs G, Rowe BH, Assendelft WJ, et al. Immobilisation for acute ankle sprain: a systematic review. Arch Orthop Trauma Surg. 2001;121(8):462-471

MacGregor K, Gerlach S, Mellor R, Hodges PW. Cutaneous stimulation from patella tape causes a differential increase in vasti muscle activity in people with patellofemoral pain. J Orthop Res. 2005;23(2):351-358. https://doi.org/10.1016/j.orthres.2004.07.006

Macrum E, Bell DR, Boling M, Lewek M, Padua D. Effect of limiting ankle-dorsiflexion range of motion on lower extremity kinematics and muscle-activation patterns during a squat. J Sport Rehabil. 2012;21(2):144-150

Malliaras P, Cook JL, Kent P. Reduced ankle dorsiflexion range may increase the risk of patellar tendon injury among volleyball players. J Sci Med Sport. 2006;9(4):304-309. https://doi.org/10.1016/j.jsams.2006.03.015

Moseley AM, Crosbie J, Adams R. Normative data for passive ankle plantarflexion-dorsiflexion flexibility. Clin Biomech (Bristol, Avon). 2001;16(6):514-521

Neely FG. Biomechanical risk factors for exercise-related lower limb injuries. Sports Med. 1998;26(6):395-413. https://doi.org/10.2165/00007256-199826060-00003 
Peng Q, Park HS, Shah P. Quantitative evaluations of ankle spasticity and stiffness in neurological disorders using manual spasticity evaluator. J Rehabil Res Dev. 2011;48(4):473-481

Powden CJ, Hoch JM, Hoch MC. Reliability and minimal detectable change of the weight-bearing lunge test: a systematic review. Man Ther. 2015;20(4):524-532.

https://doi.org/10.1016/j.math.2015.01.004

Riddle DL, Pulisic M, Pidcoe P, Johnson RE. Risk factors for plantar fasciitis: a matched case-control study. J Bone Joint Surg Am. 2003;85(5):872-887. https://doi.org/10.2106/00004623-20030500000015

Root M, Orien W, Weed J. Normal and abnormal function of the foot. Los Angeles (CA): Clinical Biomechanics Corp.; 1977

Sahrmann S. Movement system impairment syndromes of the extremities, cervical and thoracic spines. Missouri (MO): Elsevier Mosby; 2011

Sammarco GJ, Burstein AH, Frankel VH. Biomechanics of the ankle: a kinematic study. Orthop Clin North Am. 1973;4(1):75-96

Sobel E, Caselli MA, Velez Z. Effect of persistent toe walking on ankle equinus: analysis of 60 idiopathic toe walkers. J Am Podiatr Med Assoc. 1997;87(1):17-22.

https://doi.org/10.7547/87507315-87-1-17

Terada M, Pietrosimone BG, Gribble PA. Therapeutic interventions for increasing ankle dorsiflexion after ankle sprain: a systematic review. J Athl Train. 2013;48(5):696-709.

https://doi.org/10.4085/1062-6050-48.4.11

Threkland JA. The effects of manual therapy on connective tissue. Phys Ther. 1992;72(12):893-902 
Tiberio D. Pathomechanics of structural foot deformities. Phys Ther. 1988;68(12):1840-1849

Valderrabano V, Hintermann B, Horisberger M, Fung TS. Ligamentous posttraumatic ankle osteoarthritis. Am J Sports Med. 2006;34(4):612-620. https://doi.org/10.1177/0363546505281813

Vicenzino B, Paungmali A, Teys P. Mulligan's mobilization-with-movement, positional faults and pain relief: current concepts from a critical review of literature. Man Ther. 2007;12(2):98-108. https://doi.org/10.1016/j.math.2006.07.012

Wilder RP, Sethi S. Overuse injuries: tendinopathies, stress fractures, compartment syndrome, and shin splints. Clin Sports Med. 2004;23(1):55-81. https://doi.org/10.1016/S0278-5919(03)00085-1

Yoon JY, An DH, Oh JS. Plantarflexor and dorsiflexor activation during inclined walking with and without modified mobilization with movement using tape in women with limited ankle dorsiflexion. J Phys Ther Sci. 2013;25(8):993-999. https://doi.org/10.1589/jpts.25.993

Yoon JY, Hwang YI, An DH, Oh JS. Changes in kinetic, kinematic, and temporal parameters of walking in people with limited ankle dorsiflexion: pre-post application of modified mobilization with movement using talus glide taping. J Manipulative Physiol Ther. 2014a;37(5):321-325

Yoon JY, Oh JA, An DH. Three-dimensional analysis of foot motion after uphill walking with mobilization with movement using tape applied to the talocrural joint in women with limited ankle dorsiflexion. Foot Ankle Int. 2014b;35(11):1217-1225. https://doi.org/10.1177/1071100714543797 Zimny S, Schatz H, Pfohl M. The role of limited joint mobility in diabetic patients with an at-risk foot. Diabetes Care. 2004;27(4):942-946 